\title{
Asymmetric apical hypertrophy: ten years experience
}

\author{
Tsuguya Sakamoto, Keiko Amano, Yoshiyuki Hada, Chuwa Tei, Katsu Takenaka, \\ Ichiro Hasegawa and Toshiyuki Takahashi
}

The Second Department of Internal Medicine, Faculty of Medicine, University of Tokyo, Tokyo 113, Japan.

\begin{abstract}
Summary: This paper reports 10 years experience of 31 patients with asymmetric apical hypertrophy, in whom left ventricular hypertrophy involved the apex exclusively and giant $T$ wave inversion in the left precordial leads was the characteristic finding. This type of hypertrophic cardiomyopathy was observed predominantly in men over $\mathbf{4 0}$ years of age. Family history was negative and patients usually had no complaints. Left ventricular hypertrophy was evident by physical examination as in other forms of hypertrophic cardiomyopathy, but a systolic murmur was faint or absent and the second heart sound was frequently split. Electrocardiographic signs may fluctuate, and occasionally progression or regression occurs. Echocardiography including the two-dimensional method was essential for the diagnosis and left ventriculography was helpful for confirmation. To date complications have been infrequent and the prognosis seems good. The relation of asymmetric apical hypertrophy to other forms of hypertrophic cardiomyopathy is under investigation.
\end{abstract}

\section{Introduction}

Over the past 10 years, we have documented the association of giant negative $T$ waves in the left precordial leads with M-mode and two-dimensional echocardiographic findings of extremely thickened myocardium towards the left ventricular apex (Sakamoto et al., 1976). More recently, there has been considerable controversy regarding the genesis and clinical significance of this particular form of cardiac hypertrophy (asymmetric apical hypertrophy: AAH) (Toshima, 1985). We therefore summarize our longterm findings in this disease, an entity generally thought to be more frequent in Japan than elsewhere.

\section{Subjects and methods}

Thirty-one patients were found to have asymmetric apical hypertrophy in a series of 200 patients with hypertrophic cardiomyopathy, in whom clinical, electrocardiographic, phono- and mechanocardiographic, and echocardiographic studies, including two-dimensional method, were performed (Table I). More than half the cases were studied by invasive methods to confirm the diagnosis. In nearly all cases, non-invasive studies were repeated, particularly echocardiographic examination by new techniques. Almost all cases were on propranolol therapy ( 30 to $180 \mathrm{mg} /$ day) when they were re-examined. Propranolol was not discontinued

Correspondence: Tsuguya Sakamoto M.D., F.A.C.C. except for the isotope studies. The echocardiograph used was mainly an Aloka SSD-800.

The follow-up periods of patients were from 2 to 13 years.

\section{Results}

The 31 patients with asymmetric apical hypertrophy ranged in age from 25 to 70 years with a mean of 47 . Twenty-seven were male.

The patients' histories were unremarkable except for a few in whom hard work or sport had forcibly stopped breathing. Angina or chest pain was present in two cases; in which excessive alcohol intake was a probable cause. In another, chest pain developed over 10 years concomitant with slowly progressive in-

Table I Classification of hypertrophic cardiomyopathy in a total of 200 cases (December 1973 to February 1983)

\begin{tabular}{lrrr}
\hline & \multicolumn{3}{c}{ Male Fem- Total } \\
& \multicolumn{3}{c}{ ale } \\
\hline Obstructive (HOCM) & 33 & 18 & 51 \\
$\begin{array}{l}\text { Non-obstructive } \\
\text { Asymmetric septal hypertrophy (ASH) }\end{array}$ & 89 & 20 & 109 \\
Asymmetric apical hypertrophy (AAH) & 27 & 4 & 31 \\
$\begin{array}{l}\text { Asymmetric free wall hypertrophy } \\
\text { (AFWH) }\end{array}$ & 7 & 2 & 9 \\
Total & 156 & 44 & 200 \\
\hline
\end{tabular}

(C) The Fellowship of Postgraduate Medicine, 1986 
traventricular conduction disturbance. Hypertension, borderline or of mild degree, was observed in less than half the cases and there was no case of severe hypertension. Arrhythmias were rare, and lifethreatening dysrhythmias were not encountered.

Family history did not reveal a genetic factor in any case, and other types of familial hypertrophic cardiomyopathy were not present except for one family, where a distinct papillary muscle hypertrophy with the deeply inverted $\mathrm{T}$ waves was documented by left ventriculography in the brother of a case of asymmetric apical hypertrophy. To date there is no case in which a transition from asymmetric apical hypertrophy to other types of asymmetric septal hypertrophy has been observed.

Physical examination revealed no abnormality other than the heart. Cardiomegaly was not apparent physically or radiographically. However, the apical impulse was often forceful with systolic thrust and prominent ' $a$ ' wave in the apex cardiogram, with an audible atrial sound or distinct atrial sound in the phonocardiogram. The second heart sound was single or widely split with normal sequence of the two components. A systolic ejection murmur or a murmur of mitral regurgitation was uncommon, though pulsed Doppler echocardiography sometimes revealed regurgitant signals within the left atrium as is often found in patients with hypertrophic cardiomyopathy. Carotid pulse tracings had no 'spike and dome' pattern and jugular phlebogram was not contributory, though a relatively large 'a' wave was occasionally present.

Giant negative $T$ waves were present in the left precordial leads with left ventricular hypertrophy pattern evidenced by high voltage criteria (Figure 1). The depth of the inverted $T$ waves varied from 10 to $40 \mathrm{~mm}$ with an average of $15.4 \mathrm{~mm}$. Control studies of 169 cases with hypertrophic cardiomyopathy disclosed that giant $T$ wave inversion more than $10 \mathrm{~mm}$ was rare. The deepest $T$ wave was usually in $V_{5}$ or $V_{4}$ and not in $V_{6}$. The $T$ waves in lead $I$ and aVL may be inverted in severe cases. During exercise, $T$ wave inversion became less marked. Holter monitoring revealed fluctuation of the depth of the $T$ wave in some cases, but the effect of body position was not ruled out.

Long-term observation disclosed that there were minor changes in both the $T$ and QRS wave amplitudes due to the possible changes of electrode position. However, $T$ wave inversion was constant in about two thirds of cases, particularly in those patients with marked negativity. Exceptions were observed in 8 cases: in 2, the inversion was progressive, and in another 2, it developed from a nearly normal electrocardiogram over 8 years (from +3 to $-26 \mathrm{~mm}$ of the $T$ wave and from +23 to $+72 \mathrm{~mm}$ of the $R$ wave in $\mathrm{V}_{4}$ ). One patient developed marked left axis deviation over one year. In another case, incomplete and then complete right bundle branch block slowly developed

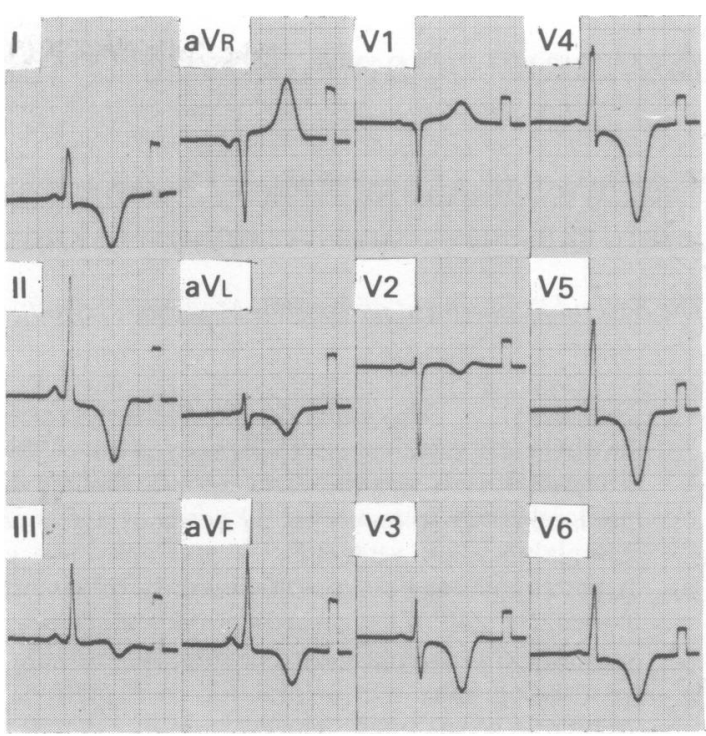

Figure 1 Twelve lead electrocardiogram. Paper speed $25 \mathrm{~mm} / \mathrm{s}$. Note the deeply inverted $T$ waves and left ventricular hypertrophy suggested by high voltage of the QRS complex. The deepest $T$ wave in $V_{4}$ reaches $-39 \mathrm{~mm}$. Precordial leads: $1 / 2 \mathrm{~N}$ standard.

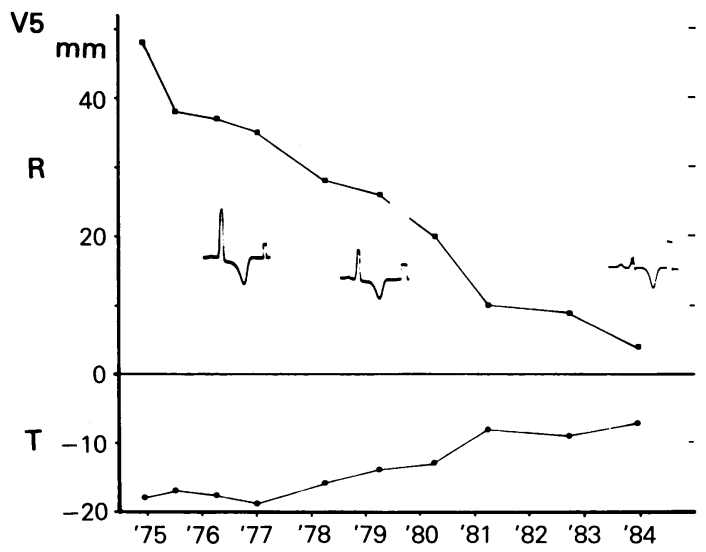

Figure 2 Time course of the amplitudes of the $R$ and $T$ waves in a case of asymmetric apical hypertrophy (37year-old man). During 10 years, the electrocardiogram was taken 27 times, and annual changes in the $R$ and $T$ waves were slowly progressive; decrease in $R$ wave was from $48 \mathrm{~mm}$ to only $5 \mathrm{~mm}$, whereas that of $T$ wave was from $-19 \mathrm{~mm}$ to $-9 \mathrm{~mm}$. The echocardiographic changes during 10 years were not distinct. The patient complained of occasional chest pain more recently, but otherwise remained essentially unchanged. 
with the concomitant progress of the inversion of the $T$ waves reaching $-18 \mathrm{~mm}$ in $\mathrm{V}_{4}$ and $\mathrm{V}_{5}$.

Regression of the electrocardiographic changes was observed in 2 cases, in which gradual reduction of both the $R$ and negative $T$ waves occurred over several years (Figure 2). In both cases, the decreased $R$ waves had several notches consistent with intraventricular conduction disturbance.

M-mode echocardiogram in the usual ultrasonic beam direction towards the tip of the mitral valve showed almost normal thickness of the interventricular septum (IVS). However, scanning towards the left ventricular apex disclosed the progressively thickened IVS and posterior wall.

Two-dimensional echocardiography was essential in the diagnosis of asymmetric apical hypertrophy. Long-axis as well as short-axis views were helpful in visualizing the thickened muscles and obliterated apex, and this was also apparent in the apical fourchamber view (Figure 3).

Follow-up study disclosed that the thickened myocardium was essentially unchanged even in cases with distinct electrocardiography regression. However, we have no data regarding the cases with newly-developed giant negative $\mathrm{T}$ waves.

Haemodynamic and angiographic studies showed no pressure gradient in the outflow tract of the left ventricle and showed systolic obliteration of the left ventricular apex in 15 of 16 patients studied. Isotope studies revealed normal ejection fractions which increased after exercise.
Deterioration was only encountered in one patient in whom angina developed in connection with alcohol intake. None developed serious arrhythmia, infective endocarditis, heart failure or sudden death. Electrocardiographic deterioration was uncommon and echocardiographic progression was rare.

\section{Discussion}

Although several cardiac and non-cardiac causes have been attributed to the genesis of giant $T$ wave inversion, localized hypertrophy of the ventricle has not been postulated (Sakamoto et al., 1976). Since the routine $\mathrm{M}$-mode echocardiogram did not disclose hypertrophy of the IVS, scanning towards the areas corresponding to the electrocardiographic changes was mandatory to detect the localized hypertrophy. The papillary muscles were thickened in nearly all cases, but most interesting was systolic obliteration of the apical cavity by the thickened myocardium. Twodimensional echocardiography was a more reliable method for observing this abnormality (Shapiro \& McKenna, 1983), and left ventriculography was helpful in identifying the findings suggested by echocardiography (Yamaguchi et al., 1979).

Asymmetric apical hypertrophy has been regarded as more frequent in Japan than elsewhere. However, there are sporadic reports from Western countries (Sheikhzadeh \& Ghabussi, 1982; Steingo et al., 1982; Kereiakes et al., 1983). The high incidence in Japan

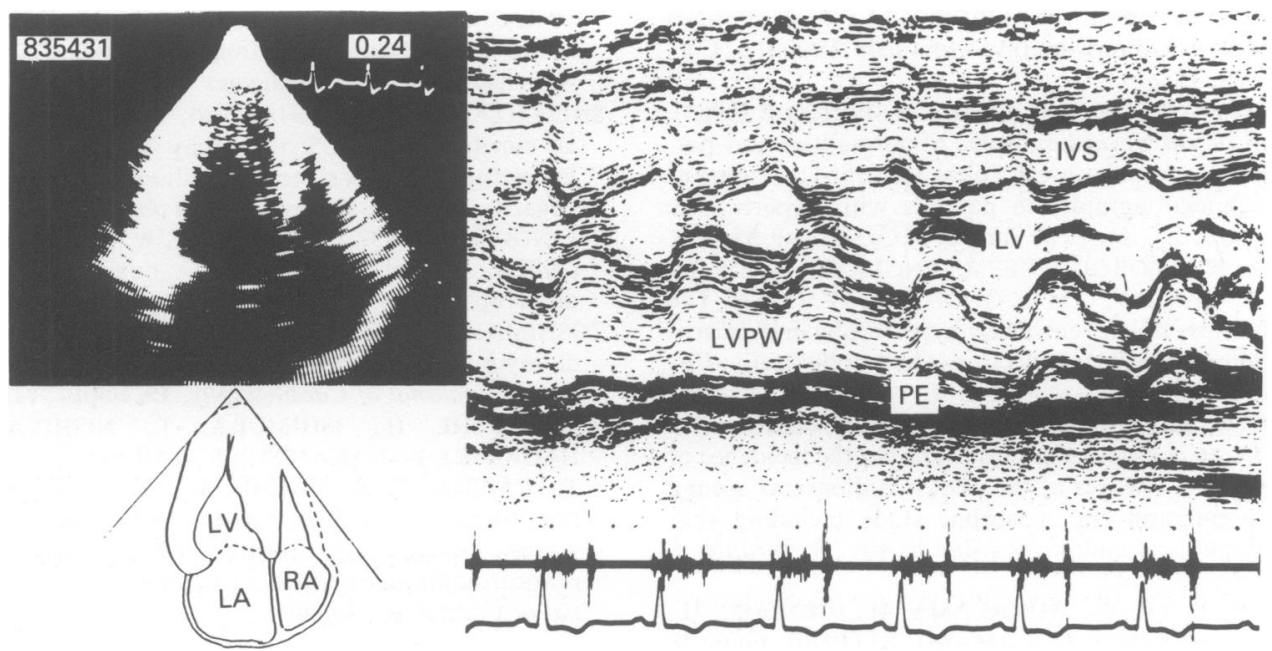

Figure 3 Apical four-chamber view of the two-dimensional and M-mode echocardiograms and the schema in a patient with asymmetric apical hypertrophy. Apical region is obliterated by the thickened myocardium in systole. The exact measurement of the thickness may be obtained by the $\mathbf{M}$-mode echocardiogram recorded by the appropriate ultrasonic beam direction determined by the two-dimensional echocardiogram. $L V=$ left ventricle; LA = left atrium; RA = right atrium; IVS = interventricular septum; LVPW = posterior wall of the left ventricle; $\mathrm{PE}=$ pericardium. 
seems to be due to the extensive electrocardiographic screening in all age groups (Bloomberg et al., 1984).

Asymmetric apical hypertrophy is generally accepted as a special form of hypertrophic cardiomyopathy (Maron et al., 1982, 1983), but genetic factors, age distribution, clinical course, and complications are not similar. We have done mass screening for 10 years, but no case of giant negative $T$ waves was detected among 171,306 schoolchildren under the age of 15 (Sakamoto et al., 1984). On the other hand, screening of adults disclosed the higher incidence: $0.085 \%$ (11 out of 12,898 ) in men and $0.028 \%$ ( 6 out of 21,232 ) in women (Morimoto et al., 1983). This seems to indicate that asymmetric apical hypertrophy develops with increase in age.

Daily or yearly fluctuation of the $\mathrm{T}$ waves mentioned by some (Sakamoto et al., 1976; Kereiakes et al., 1983; Toshima, 1985) is interesting. This may be due to the electrode malposition and the spatial

\section{References}

BLOOMBERG, G.B., HENDERSON, M.A., RAKOWSKI, H. \& WIGLE, E.D. (1984). Apical hypertrophic cardiomyopathy. Circulation, 70, II-335.

KEREIAKES, D.J., ANDERSON, D.J., CROUSE, L. \& CHATTERJEE, K. (1983). Apical hypertrophic cardiomyopathy. American Heart Journal, 105, 855.

MARON, B.J., BONOW, R.O., SESHAGIRI, T.N.R., ROBERTS, W.C. \& EPSTEIN, S.E. (1982). Hypertrophic cardiomyopathy with ventricular septal hypertrophy localized to the apical region of the left ventricle (apical hypertrophic cardiomyopathy). American Journal of Cardiology, 49, 1838.

MARON, B.J., WOLFSON, J.K., CIRÓ, E. \& SPIRITO, P. (1983). Relation of electrocardiographic abnormalities and patterns of left ventricular hypertrophy identified by 2-dimensional echocardiography in patients with hypertrophic cardiomyopathy. American Journal of Cardiology, 51, 189.

MCKENNA, W.J., BORGGREFE, M., ENGLAND, D., DEANFIELD, J., OAKLEY, C.M. \& GOODWIN, J.F. (1982). The natural history of left ventricular hypertrophy in hypertrophic cardiomyopathy: an electrocardiographic study. Circulation, 66, 1233.

MORIMOTO, S., OSAMURA, Y., MATSUMURA, K., HARADA, M. \& KOMATSU, Y. (1981). On the incidence of giant negative $\mathrm{T}$ waves of the electrocardiograms among 34,000 population and a cardiac study including ventriculography and endomyocardial biopsy. Respiration \& Circulation, 29, 1337.

SAKAMOTO, T., TEI, C., MURAYAMA, M., ICHIYASU, H., HADA, Y., HAYASHI, T. \& AMANO, K. (1976). Giant T change in the relationship between the heart and electrode induced by body position or by cardiac hypertrophy. Catecholamine release is also regarded as an important factor (Symposium, 1985), but is not conclusive.

Electrocardiographic regression of left ventricular hypertrophy observed in 2 cases deserves mention. This has been previously observed, but is rare (McKenna et al., 1982). We have no endomyocardial biopsy data, but the electrocardiographic appearance of intraventricular conduction disturbance suggests a progressive fibrotic change of the myocardium. Thus, giant negative $T$ waves with normal QRS or less marked negativity of the $T$ waves with low voltage of the QRS may occur in asymmetric apical hypertrophy. Therefore, the electrocardiographic and echocardiographic or ventriculographic correlation in asymmetric apical hypertrophy should be interpreted in considering the clinical course of the patients.

wave inversion as a manifestation of asymmetrical apical hypertrophy (AAH) of the left ventricle: echocardiographic and ultrasono-cardiotomographic study. Japanese Heart Journal, 17, 611.

SAKAMOTO, T., HADA, Y., AMANO, K., YAMAGUCHI, T. TAKENAKA, K. (1984). Population study of mitral valve prolapse in the young: eight years experience. Circulatio 70, II-162.

SHAPIRO, L.M. \& McKENNA, W.J. (1983). Distribution of left ventricular hypertrophy in hypertrophic cardiomyopathy: a two-dimensional echocardiographic study. Journal of the American College of Cardiology, 2, 437.

SHEIKHZADEH, A. \& GHABUSSI, P. (1982). A case of asymmetrical apical hypertrophy which is a form of hypertrophic nonobstructive cardiomyopathy with giant negative T-waves. Japanese Heart Journal, 23, 843.

STEINGO, L., DANSKY, R., POCOCK, W.A. \& BARLOW, J.B. (1982). Apical hypertrophic nonobstructive cardiomyopathy. American Heart Journal, 104, 635.

TOSHIMA, H. (ed.) (1985). Apical hypertrophic cardiomyopathy (asymmetrical apical hypertrophy). Symposium. Journal of Cardiography, 15, Suppl. VI 1.

YAMAGUCHI, H., ISHIMURA, T., NISHIYAMA, S., NAGASAKI, F., NAKANISHI, S., TAKATSU, F., NISHIJO, T., UMEDA, T. \& MACHII, K. (1979). Hypertrophic nonobstructive cardiomyopathy with giant negative $T$ waves (apical hypertrophy): ventriculographic and echocardiographic features in 30 patients. American Journal of Cardiology, 44, 401. 